\title{
Creating communities of care: Delineating work in the information-care relationship
}

\author{
Dr. Pam McKenzie, Associate Dean and Professor \\ Nicole Dalmer, PhD Candidate \\ Faculty of Information and Media Studies \\ The University of Western Ontario
}

\section{Introduction}

The demands of caring for a loved one with dementia may easily overwhelm the resources of a single individual, requiring the development of a community of paid and unpaid caregivers. The creation and maintenance of such a community requires a primary caregiver to engage in a great deal of work, including work involved with information seeking, sharing, creation, and management. Through a case study of an individual coordinating a community of care for a relative with Alzheimer's disease, this paper deepens our understanding of the information-care relationship by exploring how information-related work is intertwined with and contributes to the work of caring and community building, and how this work maps onto the broader context of eldercare in Canada.

\section{Context}

Alzheimer's disease and other forms of dementia are the most significant cause of disability among Canadian seniors, affecting nearly 747,000 (Alzheimer Society of Canada, 2012), a number expected to double by 2031, requiring attention from paid and unpaid communities of care. Shifts in the manner and location of care for older adults include a "withdrawal of the formal system, and [an] increasing reliance on family care providers" (Ward-Griffin \& Marshall, 2003, p. 189). Between 70 to 80 percent of the care provided to older adults is done by family and friends (Keefe, 2011), allowing older adults to age in their communities while saving costly placement in long term care facilities or hospitals.

As informal (ie, unpaid family or friend) caregivers of older adults provide care, they must find, use, translate, balance, and mediate information received from a variety of sources including health care professionals, other individuals (family members, friends, etc.), and popular print and digital sources on behalf of those they care for (Washington, Meadows, Elliott, \& Koopman, 2011; Simpson, Hall, \& Leggett, 2009). Caregivers have been shown to have complex and ever-changing information needs (Wackerbarth \& Johnson, 2002) and studies consistently report that many of these needs are unmet (Bee, Barnes, \& Luker, 2008; Greenwood, Mackenzie, Cloud, \& Wilson, 2009). Harland and Bath argue that, in the context of dementia caregiving, "information is dependent on the individual user and that 'best' information, as an objective reality, does not exist” (Harland \& Bath, 2008, p. 468).

As this paper puts forward, understanding Alzheimer's caregivers' information practices as work acknowledges the effort, time and resources required in seeking, locating, "sifting through, interpreting and dealing with the implications" of information found on behalf of loved one (Harris, 2009, p. 78). This approach also troubles the typical dichotomization of 
"workplace" and "everyday life information seeking" (Savolainen, 1995) typical in LIS scholarship.

\section{Literature review and framework of inquiry}

Previous studies of informal caregivers' information practices are largely descriptive. A survey of Canadian informal caregivers revealed a need for information regarding: pain management, navigating a complex health care system with a variety of uncoordinated services, bereavement support, respite, practical caregiving, what to expect as the illness progresses, dealing with various members and actors of the professional and volunteer care team, legal and financial questions, emotional and spiritual support, complementary and alternative therapies and culturally appropriate services (Dunbrack, 2005). Washington, Meadows, Elliott and Koopman (2011) found that informal caregivers, serving as information proxies for the older adult in their care, require information that is individualized, understandable and designed to meet their unique needs.

Caring for a loved one is a complex practice, comprising both instrumental and affective components (Holstein \& Mitzen, 2001). Although caring may be an act of love, feminist scholars also acknowledge that "care is a labor; it is work even when it goes unremunerated" (Feder Kittay, Jennings, \& Wasunna, 2005, p. 444). Much of the work associated with caring consists of what Star and Strauss (1999, p. 10, emphasis in original) call articulation work, "work that gets things back 'on track' in the face of the unexpected, and modifies action to accommodate unanticipated contingencies. The important thing about articulation work is that it is invisible to rationalized models of work." Considerable articulation work may be required in the formation and maintenance of a caring community; for example, work to navigate and coordinate information, resources and people in time and space, and to manage and document that coordination. A focus on articulation work will challenge current conceptualizations of and make visible the information work that caregivers do in both providing care for an aging family member and in maintaining the community of care that supports this provision of care.

Corbin and Strauss (1985) first described "information work" as a form of work done by people living with chronic illness. Within LIS, Hogan and Palmer (2005) and Souden (2008) have taken up the concept. Souden (2008) adopted a holistic conceptualization of information work as encompassing both cognitive and affective dimensions, recognizing both active and passive information seeking, sharing and use, and even information avoidance as work. These studies, however, have both considered information-related activities as part of the work of managing one's own chronic illness. Harris (2009) is one of few scholars to illuminate the hidden work performed by women seeking health-related information on behalf of loved ones: "regardless of where it takes place, the health-informing support women provide to others is work, although it is a form of work that is seldom acknowledged ... information management, self-care, and health maintenance remain largely invisible and underarticulated" (Harris, 2009, p. 80).

Institutional ethnography (IE) offers a method of inquiry for analyzing and contextualizing everyday activities as work. Developed by Canadian sociologist Dorothy Smith, IE understands "life as usual" to be constituted by work, which Smith understands to be "the ongoing concerting and coordinating of individuals' activities" (1999, p.7). IE begins by 
examining the routines that make up the everyday and everynight lives of individuals, but moves beyond the local to show how these routines are connected to actions of people in other (extralocal) settings and are hooked into the mandates and objectives of broader institutions such as healthcare. IE shows how the routine activities of everyday life may be mobilized to perform work on behalf of institutions. IE is widely used in professional disciplines such as education and nursing and is slowly gaining prominence in LIS. IE has been used to examine librarians' work (Crispin, 2013; Johnston \& Santos Green, 2014) and the work needed to produce and carry out children's programs at public libraries (Stooke \& McKenzie, 2009).

This paper takes up an IE approach, starting in and privileging the everyday experiences of a caregiver of an aging relative with Alzheimer's disease. Throughout this study, information activities are conceived of as work. In order to understand both the caregiver's information work and the ways that work may be coordinated by extralocal relations, we highlight we highlight the information work necessary to create and maintain the community of care that supports both the older adult and the caregiver.

\section{Methods}

This case study consists of a 55-minute interview, a 40-page interview transcript and 15 photographs. Data were analysed using the techniques of constant comparison (Strauss \& Corbin, 2008) within an abductive framework of relational analysis. An abductive strategy allows the researcher both to "focus concretely on what members of a setting do and on their accounts of what they do" (Stooke \& McKenzie, 2009, p.660) and to demonstrate how a particular instance is connected to a broader set of relations, essential in an IE inquiry. Specifically, relational analysis allows the researcher to explore and map how the work of one individual in one setting is embedded in other kinds of work, including both the work of that individual and his or her immediate community, and activities, organizations, and infrastructures originating elsewhere (Campbell \& Gregor 2002). As an analytic strategy, institutional ethnography is uniquely situated to illuminate taken-for-granted or invisible aspects of information-related work in its broader context (Courtright, 2006).

\section{Findings}

Analysis revealed the caregiver's information work as dynamic, shaped by the evolution of the older adult's illness trajectory, the availability (or absence) of support from different communities of care and the caregiver's own growing knowledge. The caregiver carefully constructed a collaged community of care to aid in the provision of care for the older adult that evolved to match the older adult's changing needs and illness progression. Multiple facets of information work emerged: creation, storage, retrieval, management and mediation. Results from this study begin to map out a complex, extralocal network that coordinates the primary caregiver's information work. While this work is concentrated in the community of care that was created in the home in which both caregiver and care recipient reside, this work radiates out and links to caring communities outside the home, including hospitals, care organizations and health care professionals.

\section{Discussion}


The composition of communities of care and the information work involved in their creation and maintenance, which this study highlights, is a crucial contribution to the evolving conversation surrounding the informatization of care. As the proportion of older adults in Canada is expected to double in the next 25 years (Statistics Canada, 2010), understanding and acknowledging the intricate care work (including information work) that family and friend caregivers are doing in the community to support our aging population is paramount. This study reveals that information work is needed when caring for an aging family member and is also necessary in building and caring for the many discrete yet overlapping communities that provide support and care for care providers and recipients.

\section{References}

Alzheimer Society of Canada. (2012). A new way of looking at the impact of dementia. Retrieved from http://www.alzheimer.ca/ /media/Files/national/Mediareleases/asc_factsheet_new_data_09272012_en.pdf

Barnes, M., Henwood, F., \& Smith, N. (2014). Information and care: A relational approach. Dementia, o(0), 1-16.

Campbell, M., \& Gregor, F. M. (2004). Mapping social relations: A primer in doing institutional ethnography. Walnut Creek, CA: Altamira Press.

Corbin, J., \& Strauss, A. (1985). Managing chronic illness at home: Three lines of work. Qualitative Sociology, 8(3), 224-247.

Corbin, J. M., \& Strauss, A. (1988). Unending work and care: Managing chronic illness at home. San Francisco: Jossey-Bass.

Courtright, C. (2007). Context in information behavior research. Annual Review of Information Science and Technology, 41, 273-306.

Crispin, J. (2013). Stumbling Around: Towards an Approach to Institutional Ethnography as a Frame of Inquiry into Library Work. In Proceedings of the Annual Conference of CAIS/Actes du congrès annuel de l'ACSI.

Dunbrack, J. (2005). The information needs of informal caregivers involved in providing support to a critically ill loved one. Retrieved from: http://www.hc-sc.gc.ca/hcssss/alt_formats/hpb-dgps/pdf/pubs/2005-info-caregiver-aidant/2005-info-caregiveraidant-eng.pdf

Feder Kittay, E., Jennings, B., \& Wasunna, A. A. (2005). Dependency, difference and the global ethic of longterm care. Journal of Political Philosophy, 13(4), 443-469.

Harland, J. A., \& Bath, P. A. (2008). Understanding the information behaviours of carers of people with dementia: A critical review of models from information science. Aging \& Mental Health, 12(4), 467-477.

Harris, R. (2009). Cyber-burdens: Emerging imperatives in women's unpaid care work. In E. Balka, E. Green \& F. Henwood (Eds.), Gender, health and information technology in context (pp. 72-87). New York: Palgrave Macmillan.

Hogan, T. P., \& Palmer, C. L. (2005). "Information work" and chronic illness: Interpreting results from a nationwide survey of people living with HIV/AIDS. Proceedings of the American Society for Information Science and Technology, 42(1).

Holstein, M., \& Mitzen, P. (Eds.). (2001). Ethics in community-based elder care. New York: Springer Publishing Company.

Hooyman, N. R., \& Gonyea, J. G. (1999). A feminist model of family care: Practice and policy directions. Journal of Women \& Aging, 11(2-3), 149-169. 
Johnston, M., \& Santos Green, L. (2014, June). Innovative Partnerships: Exploring School Librarianship through a Global Lens. In Proceedings of the Annual Conference of CAIS/Actes du congrès annuel de l'ACSI.

Keefe, J. (2011). Supporting caregivers and caregiving in an aging Canada (Rep. No. IRPP Study 23). Montreal: Institute for Research on Public Policy.

Savolainen, R. (1995). Everyday life information seeking: approaching information seeking in the context of "way of life". Library \& Information Science Research, 17(2), 259-294.

Simpson, L., Hall, M., \& Leggett, S. (2009). Gendered identities and caring: Health intermediaries and technology in rural and remote Queensland. In E. Balka, E. Green \& F. Henwood (Eds.), Gender, health and information technology in context (pp. 34-52). New York: Palgrave Macmillan.

Smith, D. E. (1999). Writing the social. Critique, theory, and investigations. Toronto: University of Toronto Press.

Souden, M. (2008). Information work in the chronic illness experience. Proceedings of the American Society for Information Science and Technology, 45(1), 1-6.

Star, S. L., \& Strauss, A. (1999). Layers of silence, arenas of voice: the ecology of visible and invisible work. Computer Supported Cooperative Work, 8(1-2), 8-30.

Statistics Canada. (2010, May 26). Population projections: Canada, the provinces and territories. Retrieved from http://www.statcan.gc.ca/dailyquotidien/100526/dq100526b-eng.htm

Stooke, R., \& McKenzie, P. J. (2009). Leisure and work in library and community programs for very young children. Library Trends, 57(4), 657-675.

Wackerbarth, S. B., \& Johnson, M. M. S. (2002). Essential information and support needs of family caregivers. Patient Education and Counseling, 47(2): 95-100.

Ward-Griffin, C., \& Marshall, V. W. (2003). Reconceptualizing the relationship between "public" and "private" eldercare. Journal of Aging Studies, 17(2), 189-208.

Washington, K. T., Meadows, S. E., Elliott, S. G., \& Koopman, R. J. (2011). Information needs of informal caregivers of older adults with chronic health conditions. Patient Education and Counseling, 83(1), 37-44. 